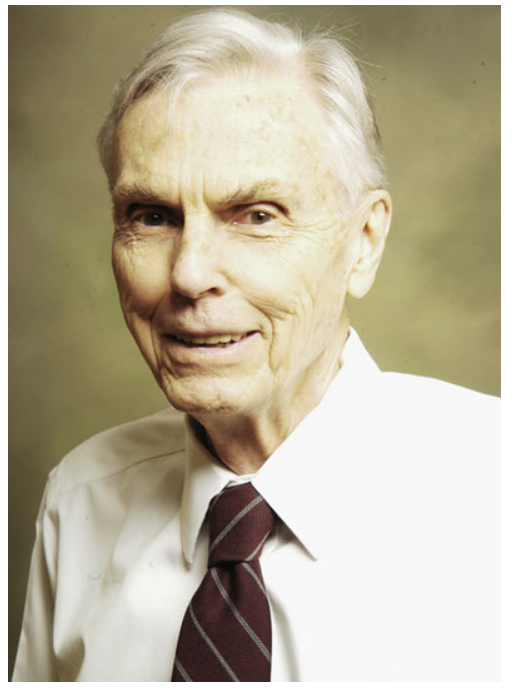

\title{
Curriculum Vitae for John Torrence Tate Jr.
}

\author{
Born: \\ March 13, 1925 in Minneapolis, USA \\ Degrees/education: Bachelor of Arts, Harvard University, 1946 \\ $\mathrm{PhD}$, Princeton University, 1950 \\ Positions: \\ Instructor, Princeton University, 1950-1953 \\ Assistant Professor, Harvard University, 1954-1959 \\ Professor, Harvard University, 1959-1966 \\ Perkins Professor, Harvard University, 1966-1990 \\ Sid W. Richardson Chair in Mathematics, University of Texas \\ at Austin, 1990-2009 \\ Visiting positions: Columbia University, 1953-1954 \\ Institute for Advanced Study, Princeton, 1959 \\ University of California at Berkeley, 1963 \\ Institut des Hautes Études Scientifiques at Bures-sur-Yvette, \\ 1965-1966 and 1968-1969 \\ Université de Paris at Orsay, 1980-1981 \\ Princeton University, 1992 \\ École Normale Supérieure, Paris, 1992 \\ Memberships: $\quad$ National Academy of Sciences, USA, 1969 \\ Académie des sciences, France, 1992 \\ London Mathematical Society (Honorary member), 1999 \\ Norwegian Academy of Science and Letters, 2010 \\ Awards and prizes: Frank Nelson Cole Prize for Number Theory, 1956 \\ Leroy P. Steele Prize for Lifetime Achievement, 1995 \\ Wolf Prize, 2002 \\ Abel Prize, 2010
}

